\title{
Loss of Local Tumor Control After Index Surgery for Spinal Metastases: A Prospective Cohort Study
}

\author{
Bart Depreitere $^{23}$, Federico Ricciardi ${ }^{2}$, Mark Arts $^{3}$, Laurent Balabaud ${ }^{4}$, Jacob Maciej Buchowski ${ }^{5}$, Cody Bunger $^{6}$, \\ Chun Kee Chung ${ }^{7}$, Maarten Hubert Coppes $^{8}$, Michael George Fehlings ${ }^{9}$, Norio Kawahara ${ }^{10}$, Chong-Suh Lee ${ }^{11}$, \\ YeeLing Leung ${ }^{12}$, Juan Antonio Martin-Benlloch ${ }^{13}$, Eric Maurice Massicotte ${ }^{9}$, Christian Mazel ${ }^{14}$, Bernhard Meyer $^{15}$, \\ Fetullah Cumhur Oner ${ }^{16}$, Wilco Peul ${ }^{17}$, Nasir Quraishi ${ }^{18}$, Yasuaki Tokuhashi ${ }^{19}$, Katsuro Tomita ${ }^{20}$, Christian Ulbricht ${ }^{21}$, \\ Jorrit Jan Verlaan ${ }^{16}$, Michael Wang ${ }^{22}$, Hugh Alan Crockard ${ }^{1}$, David Choi ${ }^{1}$
}

BACKGROUND: As survival after treatment for symptomatic spinal metastases increases, the incidence of local tumor recurrence also may increase. However, data regarding incidence and timing of recurrence or duration of survival after second surgeries are not readily available and may help to inform clinicians when to perform second surgeries.

OBJECTIVE: To identify features associated with loss of local control (LLC) at a previously treated or new spinal level.

METHODS: Clinical and surgical data were collected from a prospective cohort of 1421 patients who had surgery for symptomatic spinal metastases. Patients undergoing repeat spinal surgery for symptomatic LLC at the same or a different level were identified and analyzed.

RESULTS: In total, 3.0\% patients underwent repeat surgery for symptomatic LLC after a median interval of 184 days from the first surgery; median survival was 6.1 months after second surgery. Factors associated with second surgery for LLC were the primary tumor type, number of spinal levels, Tomita staging, Tokuhashi and Karnofsky scores, anterior surgical approach, more aggressive surgical resection, and postoperative radiotherapy. In total, 1.5\% patients were admitted for surgery for a different spinal level than the index operation after median 338 days from the first operation.

CONCLUSIONS: The likelihood for repeat surgery due to LLC cannot be accurately predicted at the time of initial presentation. Factors associated with second surgery for LLC relate to less aggressive tumor biology and better survival. Most patients had a reasonable duration of survival after second surgery.

\section{INTRODUCTION}

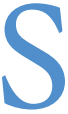
urgery for spinal metastases is effective in the management of patients with cancer when their quality of life is threatened by pathologic vertebral fracture or spinal cord

\section{Key words \\ Metastases \\ - Recurrence \\ - Repeat surgery \\ - Spine \\ - Surgery \\ - Tumor}

\section{Abbreviations and Acronyms}

GSTSG: Global Spine Tumour Study Group

LLC: Loss of local control

From the ${ }^{1}$ Department of Neurosurgery, National Hospital for Neurology and Neurosurgery, and $^{2}$ Department of Statistical Science, University College London, London, United Kingdom; ${ }^{3}$ Department of Neurosurgery, Medical Center Haaglanden, Haaglanden, The Netherlands; ${ }^{4}$ Orthopaedics and Traumatology Centre, Clinique Mutualiste de la Porte de L'Orient, Lorient, France, ${ }^{5}$ Department of Orthopaedic Surgery, Washington University School of Medicine, St. Louis, Missouri, USA; ${ }^{6}$ Department of Orthopedic Surgery, University Hospital of Aarhus, Aarhus, Denmark, 'Department of Neurosurgery, Seoul National University Hospital, Seoul, Republic of Korea; ${ }^{\boldsymbol{8}}$ Department of Neurosurgery, University Medical Centre Groningen, Groningen, The Netherlands; ${ }^{\boldsymbol{9}}$ Division of Neurosurgery and Spinal Program, University of Toronto and Toronto Western Hospital, Toronto, Canada; ${ }^{10}$ Department of Orthopedic
Surgery, Kanazawa Medical University Hospital, Kanazawa, Japan; "Department of Orthopaedic Surgery, Samsung Medical Center, Sungkyunkwan University School of Medicine, Seoul, Republic of Korea; ${ }^{12}$ Department of Orthopaedics, Musgrove Park Hospital, Taunton, United Kingdom; ${ }^{13}$ Spinal Unit, Hospital Universitario Dr Peset, Valencia, Spain;

${ }^{14}$ Department of Orthopedic Surgery, L'Institut Mutualiste Montsouris, Paris, France, ${ }^{15}$ TUM School of Medicine, Technische Universitat Munchen, Munich, Germany; ${ }^{16}$ Department of Orthopedic Surgery, University Medical Center Utrecht, Utrecht, The Netherlands;

${ }^{17}$ Department of Neurosurgery, Leiden University Medical Centre, Leiden, The Netherlands, ${ }^{18}$ Centre for Spine Studies and Surgery, Queens Medical Centre, Nottingham, United Kingdom; ${ }^{19}$ Department of Orthopaedic Surgery, Nihon University School of Medicine, Tokyo, Japan; ${ }^{20}$ Department of Orthopedic Surgery, Kanazawa University, Kanazawa, Japan;

${ }^{21}$ Department of Neurosurgery, Charing Cross Hospital, London, United Kingdom;

${ }^{22}$ Department of Neurosurgery, Jackson Memorial Hospital, University of Miami, Miami, USA; and ${ }^{23}$ Division of Neurosurgery, University Hospitals Leuven, Leuven, Belgium;

To whom correspondence should be addressed: David Choi, Ph.D.

[E-mail: david.choi@uclh.nhs.uk]

Citation: World Neurosurg. (2018).

https://doi.org/10.1016/j.wneu.2018.04.170

Journal homepage: www. WORLDNEUROSURGERY.org

Available online: www.sciencedirect.com

1878-8750/\$ - see front matter @ 2018 Elsevier Inc. All rights reserved. 
compression. $^{\mathrm{I}-5}$ The evolution of spinal surgery techniques over the past 2 decades have enabled direct spinal cord or nerve root decompression and tumor resection in combination with tailored spine reconstruction. Hence, the goal of surgery is to reduce pain and to restore or safeguard neurologic function. The incidence of spinal metastases has been increasing since treatment for oncologic disorders has improved over recent years, resulting in longer patient survival. ${ }^{6,7}$ Improved survival also has led to the possibility of patients living long enough to experience loss of local tumor control after surgery and radiotherapy for symptomatic spinal metastases.

Although Patchell et al. ${ }^{\mathrm{I}}$ in their landmark paper demonstrated that surgery is advantageous when a patient first presents with symptoms, little is known about the outcome after revision surgery for local tumor recurrence. To inform the complex decision-making process when a patient presents with symptomatic spinal metastasis, scoring systems have been developed to predict patient survival. ${ }^{8-\mathrm{II}}$ Moreover, more detailed decision algorithms have been suggested to decide whether more aggressive surgical resection is appropriate. ${ }^{\mathrm{I2}, \mathrm{I} 3}$ Therefore, recurrent spinal cord compression from loss of local control (LLC) could be considered a shortcoming of the initial choice of surgical technique or approach. Although it is thought that radical en bloc resections may reduce the incidence of LLC, ${ }^{9}$ such interventions are associated with greater surgical risks. ${ }^{\text {I4 }}$ The reported incidence of LLC after piecemeal intralesional debulking varies between $1.4 \%$ and $32 \%$, depending on the definition used for LLC: $32 \%$ for radiologic LLC, ${ }^{15} 20 \%-22 \%$ for symptomatic LLC, ${ }^{\mathrm{I} 6, \mathrm{I7}}$ and $\mathrm{I} .4 \%-8.4 \%$ for patients effectively undergoing revision surgery. ${ }^{18,19}$ Laufer et al. ${ }^{20}$ reported a median survival of 9 months after repeat surgery for recurrent spinal metastasis and a $65 \%$ rate of preserved ambulation. Therefore, the consideration of repeat surgery can be relevant in terms of safeguarding quality of life in patients with spinal metastasis with sufficiently long survival.

The aim of the current study was to identify possible predictors of recurrent spinal symptoms resulting from loss of local tumor control at a previously treated level and to document preoperative status and survival after repeat surgery. We also reviewed data for patients who underwent a second operation for new spinal metastases at a different level to the index operation. The study uses data from the Global Spine Tumour Study Group (GSTSG) database. This database is the largest prospective surgical series of patients with symptomatic spinal metastases. Other GSTSG publications have looked at subsets of patients from the same database to study aspects of metastatic spine disease. ${ }^{2 \mathrm{I}-23}$

\section{METHODS}

\section{Patients and GSTSG Database}

For this study, data from consecutive patients who were admitted for surgery for symptomatic spinal metastases at 23 orthopedic spinal or neurosurgical centers in Belgium, Canada, China, Denmark, France, Germany, Japan, The Netherlands, South Korea, Spain, the United Kingdom, and the United States were longitudinally followed up in a research database. Indications for surgery were spinal pain, instability, or neurologic symptoms. Patients were analyzed if recruited between March 200I and
September 20I6. Patients were excluded if they were unable to consent or if they had a primary bone tumor of the spine.

A secure Internet database was developed by the GSTSG and hosted on computer servers with secure socket-layer Thawtecertificated encryption. Anonymized validated data were prospectively entered by surgeons at the spine centers. Case record forms were locked 4 weeks after initial data entry so that data could not be altered or amended. Local institutional ethical approvals were granted in all centers.

\section{Variables}

Preoperative data at the time of initial surgery included age, sex, primary tumor type, spinal level(s) affected by tumor, Tomita classification of tumor extent, ${ }^{24}$ type and number of visceral metastases, extraspinal bone metastases, Tomita prognostic score,${ }^{9}$ Tokuhashi prognostic score, ${ }^{\text {IO }}$ preoperative radiation therapy, ambulatory status, Frankel score, sphincter control, visual analog scale for axial/radicular pain, Karnofsky performance index, American Society of Anesthesiologists score, and the EuroQol 5-Dimension questionnaire. Surgical data included type of surgery, ${ }^{7}$ number of spinal levels of tumor resection and fixation, and intraoperative and postoperative complications and ambulatory status. Follow-up data included radiotherapy and other oncologic treatments, staging data, ambulatory status, Frankel score, and bladder control at or close to 3, 6, 12, 24, 36, and 48 months intervals after surgery or to date of death.

\section{Definition of LCC}

LLC was defined as repeat surgery at a previously surgically treated level for recurrent tumor affecting the same level or same level with extension to neighboring levels. Also shifts in levels were included with a maximum of 2 level shifts. Patients whose followup was $<$ I year and who did not have a date of death documented were deleted from all comparisons to avoid bias in reporting LLC resulting from loss of follow up. Other reasons for repeat surgery, such as infection or instrumentation failure, were excluded.

\section{Definition of New Tumor Occurrence}

The incidence of patients presenting with and undergoing repeat surgery for further metastatic tumor at a new level, which was discrete and noncontiguous with the original site of surgery, was documented.

\section{Analysis}

The analysis included descriptive and comparative results from I42I patients. The following variables were documented in the descriptive analysis: proportion of patients, time interval to LLC, primary tumor type, spinal level, initial Tomita classification of tumor extent (Figure 1), initial surgery type, symptoms at LLC, metastatic load at LLC, and survival after repeat surgery. There was incomplete follow-up data for neurologic status and quality of life after second surgery to enable statistical analysis after repeat surgery.

In the comparative analysis, variables associated with initial presentation and treatment were compared between the patient groups that underwent repeat surgery for LLC or only had I surgery: age, sex, primary tumor type, number of affected spinal levels, Tomita classification of tumor extent, type and number of 


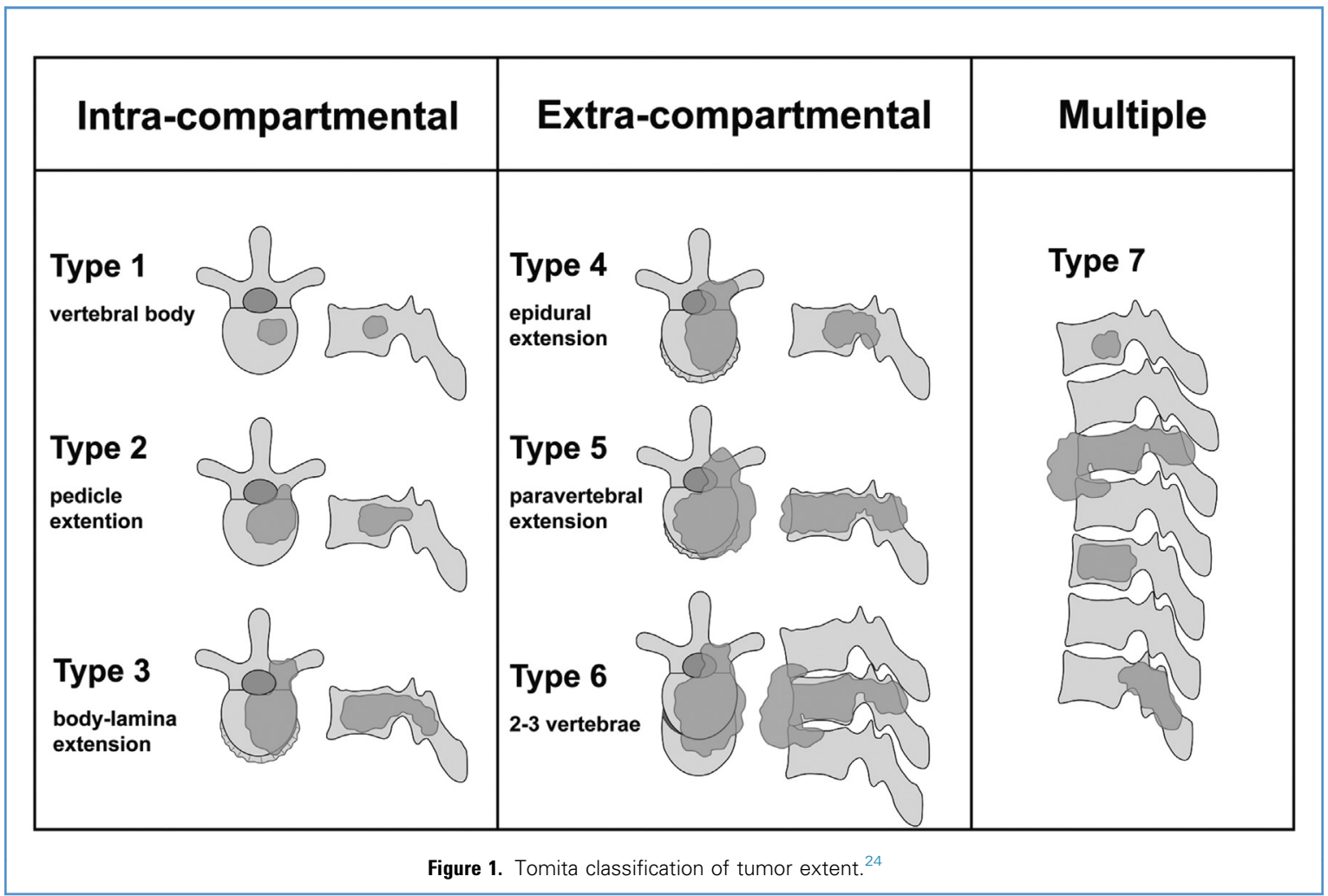

visceral metastases, presence of extraspinal bone metastases, Tomita score, Tokuhashi score, Frankel score, sphincter control, Karnofsky performance index, American Society of Anesthesiologists score, and EuroQol 5-Dimension index at initial presentation as well as surgical approach and surgery type, pre/postoperative radiation therapy, and postoperative chemotherapy were considered and their association, with the aforementioned grouping compared by univariate and multivariate analyses.

Data were analyzed by encrypted download. Data handling and statistical tests were performed with Stata I3.I software (StataCorp LLC, College Station, Texas, USA). Data distributions were reviewed for skew deviation before descriptive analysis and means or medians were presented accordingly. Kaplan-Meier plots were produced to assess survival rates. Comparative analyses were performed in a univariate fashion with $t$ tests and Pearson $\chi^{2}$ tests according to the nature of the variables, and logistic regression was used for multivariate analyses. P values of less than 0.05 were considered significant. The Strengthening The Reporting of OBservational Studies in Epidemiology (STROBE) checklist for cohort studies has been implemented in this study.

\section{RESULTS}

There were 42 of I42I (3.0\%) patients who underwent repeat surgery for LLC. The median time from the first surgery to the repeat surgery was 184 days (interquartile range $87-343$ days). Primary tumor types are presented in Table 1. In the patients who developed LLC, renal and prostate tumors were most frequent (both $23.8 \%$ ), followed by
Table 1. Primary Tumor Types of the Overall Cohort ( $n=1421)$ and of the Patients with Loss of Local Control $(n=42)$, with the Proportion of Patients in Each Primary Tumor Type

\begin{tabular}{|lcc|}
\hline Tumor Type & $\begin{array}{c}\text { N with Tumor } \\
\text { at Initial Surgery }\end{array}$ & $\begin{array}{c}\boldsymbol{N}(\%) \text { with Repeat Surgery } \\
\text { for Recurrent Tumor }\end{array}$ \\
\hline Breast & 242 & $3(7.14 \%)$ \\
\hline Colorectal & 70 & $6(14.29 \%)$ \\
\hline Renal & 156 & $10(23.81 \%)$ \\
\hline Lung & 202 & $3(7.14 \%)$ \\
\hline Prostate & 237 & $10(23.81 \%)$ \\
\hline Myeloma & 65 & 0 \\
\hline Gastrointestinal & 26 & 0 \\
\hline Liver & 32 & $2(4.76 \%)$ \\
\hline Bladder & 22 & 0 \\
\hline Lymphoma & 19 & 0 \\
\hline Melanoma & 19 & $1(2.38 \%)$ \\
\hline Sarcoma & 33 & $3(7.14 \%)$ \\
\hline Thyroid & 24 & $1(2.38 \%)$ \\
\hline Other specified & 125 & $2(4.76 \%)$ \\
\hline Other/unknown & 149 & $1(2.38 \%)$ \\
\hline
\end{tabular}


Table 2. Symptoms at Initial Presentation for the Entire Group

(Left Column) and at the Time of Presentation with Loss of Local Control (Right Column)

\begin{tabular}{|c|c|c|}
\hline & $\begin{array}{c}\text { Symptoms Before } \\
\text { Initial Surgery, } \\
N=1065\end{array}$ & $\begin{array}{c}\text { Symptoms Before } \\
\text { Repeat Surgery } \\
\text { for Loss of Local } \\
\text { Control, } N=36^{*}\end{array}$ \\
\hline \multicolumn{3}{|l|}{ Pain, $n(\%)$} \\
\hline Back & $432(40.6 \%)$ & $13(36.1 \%)$ \\
\hline None & $74(7.0 \%)$ & $6(16.7 \%)$ \\
\hline Radicular & $222(20.9 \%)$ & $3(8.3 \%)$ \\
\hline $\begin{array}{l}\text { Radicular and } \\
\text { back pain }\end{array}$ & $337(31.6 \%)$ & $14(38.96 \%)$ \\
\hline $\begin{array}{l}\text { Pain intensity, } \\
\text { median (IOR) }\end{array}$ & $7(4-8)$ & $4(2-6)$ \\
\hline \multicolumn{3}{|c|}{ Frankel score, $n(\%)$} \\
\hline A & $21(1.5 \%)$ & $1(2.8 \%)$ \\
\hline B & $53(3.8 \%)$ & $1(2.8 \%)$ \\
\hline C & $317(22.6 \%)$ & $5(13.9 \%)$ \\
\hline D & $472(33.7 \%)$ & $17(47.2 \%)$ \\
\hline$E$ & $538(38.4 \%)$ & $12(33.3 \%)$ \\
\hline \multicolumn{3}{|c|}{ Sphincter score, $n(\%)$} \\
\hline No problems & $803(76.0 \%)$ & $27(75.0 \%)$ \\
\hline Impaired & $174(16.5 \%)$ & $6(16.7 \%)$ \\
\hline Incontinent & $80(7.6 \%)$ & $3(8.3 \%)$ \\
\hline \multicolumn{3}{|c|}{$\begin{array}{l}\text { IQR, interquartile range. } \\
{ }^{*} \text { Note that detailed information on symptoms at presentation with loss of local control } \\
\text { was only available in } 36 \text { of } 42 \text { patients. }\end{array}$} \\
\hline
\end{tabular}

colorectal tumors (I4.3\%). Levels where LLC developed were distributed between $\mathrm{C}_{5}$ and the sacrum with a predilection for the thoracic spine (22 of 34 with documented level information). Tomita classification of tumor extent at initial presentation varied between $\mathrm{I}$ and 7 with a median of 5 , and the large majority (33/42) being extracompartmental. The majority of patients $(28 / 42)$ underwent a palliative procedure at initial presentation, whereas more extensive tumor removal had been performed in I4 patients, 3 of those having undergone an extralesional en bloc resection and 4 an intralesional complete resection.

Symptoms at the time of LLC are shown in Table 2. In comparison with the overall initial presentation, there were more patients with no pain or with both axial and radicular pain at presentation of LLC, and pain intensity seemed to be slightly lower. Fewer patients were neurologically intact, and a greater proportion had a Frankel D score. At the time of LLC, 6 of 42 patients had brain metastases, 5 had liver metastases, 9 had lung metastases, and 26 had other metastases. At the time of initial surgery, none of these patients had brain metastases, but 6 had liver metastases, 9 had lung metastases, and 34 had other metastases. Therefore, I patient had a good response to treatment for liver metastasis, and 8 patients

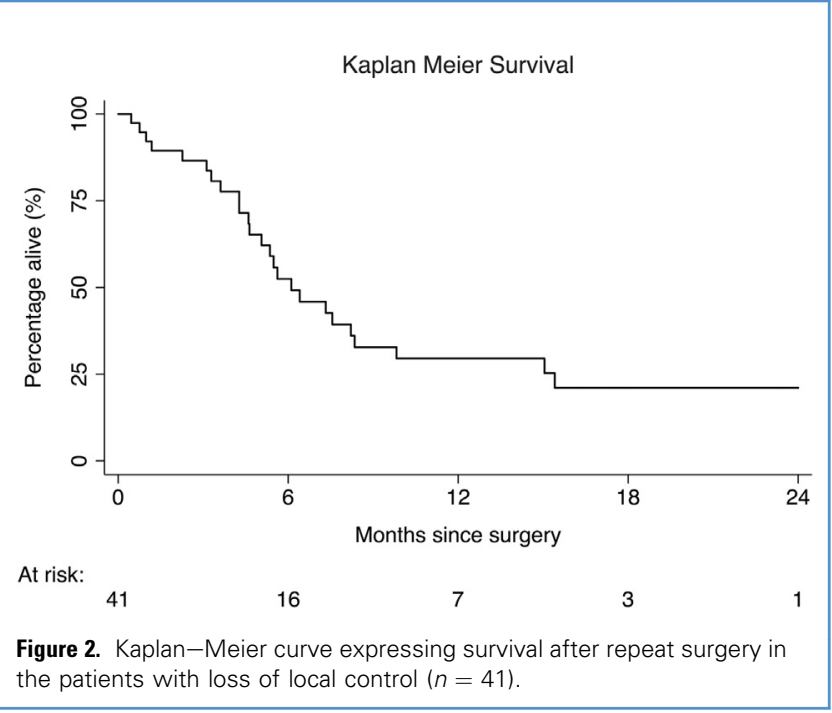

responded to systemic treatment for other metastases. Survival data were available in $4 \mathrm{I}$ patients: the median survival post second surgery was 6.I months (interquartile range 4.3- I5.4 months, Figure 2).

Intraoperative complication rates were greater in the revision surgery group compared with initial surgery. Of 42 patients who underwent revision surgery, 5 (II.9\%) had neurologic complications of inadvertent dural tear at the time of surgery, but none of these patients had vascular or visceral complications. At the time of the index surgery, I7 of I42I (I.2\%) patients had neurologic complications, of whom $5(0.4 \%)$ had a dural tear.

When we compared the initial presenting features of patients who did not develop LLC with the 42 patients who eventually developed LLC (Table 3), primary tumor type had a significantly different distribution in both groups $(P=0.003)$. Later LLC was associated with an initially greater number of affected spinal levels $(P=0.04)$. Also, patients who later developed LLC initially had better Tokuhashi scores $(\mathrm{P}=0.02)$, lower Tomita scores for tumor extent $(\mathrm{P}=0.02)$, and greater Karnofsky scores $(P=0.02)$. In the LLC group, more patients had undergone anterior-only surgery $(\mathrm{P}<\mathrm{o} . \mathrm{oI})$, and more patients had undergone more aggressive surgery types at initial surgery $(\mathrm{P}<\mathrm{o.oI})$. Finally, in the LLC group, more patients had undergone postoperative radiotherapy $(\mathrm{P}<\mathrm{o} . \mathrm{or})$. The multivariate analysis, however, did not yield any particular variable that was strongly and independently predictive for later LLC, but this was likely to be due to small sample size of the group undergoing surgery for LLC.

Of I42I patients, 2I required surgery for tumor occurrence at a different level to the original operation, after a median interval of 338 days (interquartile range $84-534$ days). Three of these patients (I4.3\%) had a primary diagnosis of renal carcinoma, 3 patients ( $14.3 \%$ ) had myeloma, and 2 patients ( $9.5 \%$ ) presented with breast carcinoma, 2 with colorectal cancer, and 2 with lung carcinomas. Multiple regression analysis did not reveal any preoperative factors that were associated with new tumor occurrence at a different level to the first operation, although the number of patients requiring 
Table 3. Comparison of Patient, Oncologic, and Treatment Variables at Initial Presentation and for Patients with Only One Surgery

$(n=1360)$ and Patients Who Underwent Repeat Surgery for Loss of Local Control $(n=42)$

\begin{tabular}{|c|c|c|c|}
\hline & $\begin{array}{l}\text { Initial Variables of Patients with } \\
\text { Only One Surgery, } N=1360\end{array}$ & $\begin{array}{l}\text { Initial Variables of Patients with Later Repeat } \\
\text { Surgery for Loss of Local Control, } N=42\end{array}$ & $P$ Value \\
\hline Age at surgery, years, mean (SD) & $61.1(12.3)$ & $63.5(11.8)$ & 0.23 \\
\hline Sex, male, $n(\%)$ & $798(58.7 \%)$ & $28(66.7 \%)$ & 0.30 \\
\hline First surgery type, $n(\%)$ & & & 0.24 \\
\hline Emergency & $167(19.2 \%)$ & $5(11.9 \%)$ & \\
\hline Scheduled/urgent & $705(80.1 \%)$ & $37(88.1 \%)$ & \\
\hline Tumor excision, $n(\%)$ & & & 0.00 \\
\hline Palliative & $678(54.55 \%)$ & $10(23.81 \%)$ & \\
\hline Piecemeal debulking & $343(27.59 \%)$ & $18(42.86 \%)$ & \\
\hline Piecemeal vertebrectomy & $57(4.59 \%)$ & $7(16.67 \%)$ & \\
\hline En bloc intralesional & $69(5.55 \%)$ & $4(9.52 \%)$ & \\
\hline En bloc extralesional & $96(7.72 \%)$ & $3(7.14 \%)$ & \\
\hline Number of levels affected, median (IOR) & $1(0-3)$ & $2(1-3)$ & 0.04 \\
\hline Karnofsky score, mean (SD) & $61.6(20.3)$ & $69.3(19.4)$ & 0.02 \\
\hline EQ-5D index, median (IOR) & $0.37(0.13-0.69)$ & $0.49(0.26-0.78)$ & 0.11 \\
\hline Frankel category, $n(\%)$ & & & 0.06 \\
\hline A & $21(1.55 \%)$ & $0(0.00 \%)$ & \\
\hline B & $54(3.97 \%)$ & $0(0.00 \%)$ & \\
\hline C & $310(22.81 \%)$ & $7(16.67 \%)$ & \\
\hline $\mathrm{D}$ & $461(33.92 \%)$ & $10(23.81 \%)$ & \\
\hline E & $513(37.75 \%)$ & $25(59.52 \%)$ & \\
\hline ASA, $n(\%)$ & & & 0.38 \\
\hline 1 & $80(8.58 \%)$ & $6(14.29 \%)$ & \\
\hline 2 & $393(42.17 \%)$ & $14(33.33 \%)$ & \\
\hline 3 & $413(44.31 \%)$ & $21(50.00 \%)$ & \\
\hline$>3$ & $46(4.94 \%)$ & $1(2.38 \%)$ & \\
\hline Metastatic tumor diagnosis, $n(\%)$ & & & 0.003 \\
\hline Breast & $239(17.33 \%)$ & $3(7.14 \%)$ & \\
\hline Colorectal & $64(4.64 \%)$ & $6(14.29 \%)$ & \\
\hline Renal & $146(10.59 \%)$ & $10(23.81 \%)$ & \\
\hline Lung & $199(14.43 \%)$ & $3(7.14 \%)$ & \\
\hline Prostate & $227(16.46 \%)$ & $10(23.81 \%)$ & \\
\hline Myeloma & $65(4.71 \%)$ & $0(0.00 \%)$ & \\
\hline Gastric & $26(1.89 \%)$ & $0(0.00 \%)$ & \\
\hline Liver & $30(2.18 \%)$ & $2(4.76 \%)$ & \\
\hline Bladder & $22(1.60 \%)$ & $0(0.00 \%)$ & \\
\hline Lymphoma & $19(1.38 \%)$ & $0(0.00 \%)$ & \\
\hline Melanoma & $18(1.31 \%)$ & $1(2.38 \%)$ & \\
\hline
\end{tabular}


Table 3. Continued

\begin{tabular}{|c|c|c|c|}
\hline & $\begin{array}{l}\text { Initial Variables of Patients with } \\
\text { Only One Surgery, } N=1360\end{array}$ & $\begin{array}{l}\text { Initial Variables of Patients with Later Repeat } \\
\text { Surgery for Loss of Local Control, } N=42\end{array}$ & $P$ Value \\
\hline Sarcoma & $30(2.18 \%)$ & $3(7.14 \%)$ & \\
\hline Thyroid & $23(1.67 \%)$ & $1(2.38 \%)$ & \\
\hline Other specified & $123(8.92 \%)$ & $2(4.76 \%)$ & \\
\hline Other unknown & $148(10.73 \%)$ & $1(2.38 \%)$ & \\
\hline \multicolumn{4}{|l|}{ Assessment of clinical status, $n(\%)$} \\
\hline Clinical examination & $792(91.7 \%)$ & $40(95.2 \%)$ & 0.41 \\
\hline CT scan & $647(74.9 \%)$ & $28(66.7 \%)$ & 0.23 \\
\hline PET scan & $104(12.0 \%)$ & $3(7.1 \%)$ & 0.34 \\
\hline Radioisotope scan & $57(6.6 \%)$ & $3(7.4 \%)$ & 0.89 \\
\hline US scan & $33(3.8 \%)$ & $0(0.0 \%)$ & 0.20 \\
\hline MRI scan & $755(87.4 \%)$ & $39(92.9 \%)$ & 0.29 \\
\hline \multicolumn{3}{|l|}{ Tomita score, $n(\%)$} & \multirow[t]{5}{*}{0.55} \\
\hline $2-3$ & $314(31.34 \%)$ & $16(38.10 \%)$ & \\
\hline $4-5$ & $192(19.16 \%)$ & $8(19.05 \%)$ & \\
\hline $6-7$ & $235(23.45 \%)$ & $11(26.19 \%)$ & \\
\hline $8-10$ & $261(26.05 \%)$ & $7(16.67 \%)$ & \\
\hline \multicolumn{3}{|l|}{ Tomita classification, $n(\%)$} & \multirow[t]{8}{*}{0.02} \\
\hline 1 & $28(2.80 \%)$ & $3(7.14 \%)$ & \\
\hline 2 & $32(3.20 \%)$ & $5(11.90 \%)$ & \\
\hline 3 & $61(6.11 \%)$ & $1(2.38 \%)$ & \\
\hline 4 & $115(11.51 \%)$ & $7(16.67 \%)$ & \\
\hline 5 & $206(20.62 \%)$ & $5(11.90 \%)$ & \\
\hline 6 & $166(16.62 \%)$ & $8(19.05 \%)$ & \\
\hline 7 & $391(39.14 \%)$ & $13(30.95 \%)$ & \\
\hline \multicolumn{3}{|l|}{ Tokuhashi score, $n(\%)$} & \multirow[t]{4}{*}{0.02} \\
\hline $0-8$ & $408(48.46 \%)$ & $12(28.57 \%)$ & \\
\hline $9-11$ & $306(36.34 \%)$ & $18(42.86 \%)$ & \\
\hline $12-15$ & $128(15.20 \%)$ & $12(28.57 \%)$ & \\
\hline Preoperative radiotherapy, yes, $n(\%)$ & $213(21.6 \%)$ & $6(15.0 \%)$ & 0.32 \\
\hline Postoperative radiotherapy, yes, $n(\%)$ & $367(27.0 \%)$ & $24(57.1 \%)$ & 0.00 \\
\hline Follow-up chemotherapy, yes, $n(\%)$ & $289(21.3 \%)$ & $12(28.6 \%)$ & 0.26 \\
\hline Posterior surgery, yes, $n(\%)$ & $921(67.7 \%)$ & $29(69.1 \%)$ & 0.86 \\
\hline Anterior surgery, yes, $n(\%)$ & $133(9.8 \%)$ & $8(19.1 \%)$ & 0.05 \\
\hline \multicolumn{3}{|l|}{ Extraspinal bone mets, $n(\%)$} & \multirow[t]{4}{*}{0.54} \\
\hline 0 & $375(44.3 \%)$ & $22(52.4 \%)$ & \\
\hline $1-2$ & $259(30.6 \%)$ & $12(28.6 \%)$ & \\
\hline$\geq 3$ & $212(26.1 \%)$ & $8(19.1 \%)$ & \\
\hline
\end{tabular}




\begin{tabular}{|c|c|c|c|}
\hline & $\begin{array}{l}\text { Initial Variables of Patients with } \\
\text { Only One Surgery, } N=1360\end{array}$ & $\begin{array}{l}\text { Initial Variables of Patients with Later Repeat } \\
\text { Surgery for Loss of Local Control, } N=42\end{array}$ & $P$ Value \\
\hline Surgical approach & & & 0.00 \\
\hline Anterior & $43(4.3 \%)$ & $7(17.5 \%)$ & \\
\hline Combined anterior and posterior & $109(11.0 \%)$ & $3(7.5 \%)$ & \\
\hline Lateral & $2(0.2 \%)$ & $1(2.5 \%)$ & \\
\hline Posterior & $840(84.5 \%)$ & $29(72.5 \%)$ & \\
\hline
\end{tabular}

surgery at a new spinal level was small, probably leading to underpowered statistical analysis.

\section{DISCUSSION}

In this analysis of the characteristics of patients with LLC after initial surgery for spinal metastases, we found that the incidence of LLC, defined as patients requiring repeat surgery at the same level as the first operation, was as low as $3.0 \%$. Hence, this means that in the large majority of this patient cohort, for whom spinal surgery was part of the initial management, local control of the spinal metastasis was maintained until death or for at least I year, or LLC did not result in a decision for repeat surgery. Patients with metastases from renal cell carcinoma more commonly presented with LLC (23.8\%), perhaps due to the relative radioresistance of these tumors. Good postoperative quality of life is achievable and maintained in patients with a preoperative Karnofsky score $>60,{ }^{21}$ and it is likely that symptomatic LLC with reasonable functional status would have been referred for surgery. This supports the idea that initial surgery for spinal metastasis should not be denied based on a fatalistic attitude that spinal cord compression will inevitably recur. In previously published retrospective series, the incidence of repeat surgery for LLC was reported to vary between 5 of 289 $(\mathrm{I} .7 \%)^{\mathrm{I} 8}$ and 9 of $\mathrm{IO} 7(8.4 \%) .{ }^{\mathrm{I} 9}$ When LLC occurred in our cohort, it was relatively early in the postoperative course, with a median interval of just over half a year. We found that the clinical presentation at LLC was slightly different to that before initial surgery, with somewhat lower pain scores and a greater proportion of motor impairment. This is likely to be due to the fixation of the first surgery maintaining mechanical stability, and therefore clinical deterioration is more likely to be neurologic as the tumor recurs a second time. The overall metastatic load did not seem to be greater at the time of LLC than at initial presentation. The median survival after the repeat surgery was half a year. In other words, median survival after the initial surgery was approximately I year, and those patients had undergone 2 spinal surgeries in the meantime. Twenty-one patients ( $\mathrm{I} .5 \%$ ) presented with new metastases at a different level to the initial operated level, suggesting that surgery was effective at maintaining local tumor control in these patients.

It remains a matter of debate whether repeat surgery is beneficial to patients with symptomatic LLC. Laufer et al justified reoperation by reporting $65 \%$ of preserved ambulation after repeat surgery in 39 patients, with an overall complication rate of $5 \% .{ }^{20}$ Lau et al.,${ }^{25}$ in a report of 32 recurrences defined by imaging, found that the 14 patients who underwent repeat surgery were more likely to remain ambulatory than those who did not receive further surgery (I00.0\% vs. $66.7 \%, P=0.024$ ), and maintained a greater mean Karnofsky score (72.7 vs. 56.9, $\mathrm{P}=0.065)$. The median survival time after reoperation was 12.4 months in the series by Laufer et al. However, Laufer et al. ${ }^{20}$ emphasized a strong influence from selection bias, in that repeat surgery was more likely to be offered to patients with adequate systemic cancer control. Figures on survival after repeat surgery vary significantly in the literature, with Chataigner and Onimus ${ }^{\text {I9 }}$ reporting a mean survival of 4.45 months in 17 patients and Jansson et al. ${ }^{16}$ a mean survival of 6 months. Given this heterogeneity, decisions in clinical practice should be individualized and take all relevant variables into account, including oncological, neurologic, mechanical, and patient factors, when faced with recurrent metastatic disease.

The main aim of the present study was to identify predictors for LLC. This may inform surgical decision-making and in particular the extent of proposed operation. In a series by Yoshioka et al. ${ }^{26}$ on 22 patients who underwent a spondylectomy of 3 more levels, among I4 metastasis cases, no recurrences were observed for at least I year. In another study from the group of Tomita, Io patients with spinal metastases for whom en bloc spondylectomy was performed had no recurrences after Io years of follow up. ${ }^{27}$ Complication rates for en bloc spondylectomy vary widely ${ }^{\mathrm{I}, 24,28,29}$ and partially depends on surgeons' caseload and expertise. Whether more radical surgical removal of metastatic spinal lesions affects survival is unclear; a different question is whether en bloc resection might lower the rate of LLC.

However, from our analysis, it was not possible to clearly identify predictors of LLC, due to the low rate of LCC $(3 \%)$ in our and other series. The main variables associated with the likelihood of LLC were the primary tumor type, greater number of affected spinal levels, better Tokuhashi score, anterior-only surgery, more aggressive surgery at the initial presentation, and postoperative radiotherapy. In their retrospective analysis of factors associated with recurrence in 32 patients, Lau et al. ${ }^{15}$ found an association with primary tumor type, postoperative radiotherapy, number of spinal levels, and length of survival.

Primary tumors associated with a greater proportion of LLC in our series were renal, prostate, and colorectal carcinomas. A 
relation between renal carcinoma and likelihood of recurrence also has been seen in the series of Lau et al., ${ }^{15}$ Chataigner and Onimus, ${ }^{19}$ and Weigel et $\mathrm{al}^{\mathrm{I7}}$ and may be associated with their high vascularity. ${ }^{30}$ Similar to the current analysis, Lau et al. found that rates of postoperative radiotherapy were greater in the LLC group, and they explained this finding by a possible relation between radiotherapy and longer survival, which in their series was a variable associated with a greater proportion of recurrences. In our series, apart from tumor biology and number of affected spinal levels, all other variables associated with surgery for LLC are factors that can potentially be related to longer survival: greater Karnofsky and Tokuhashi scores and postoperative radiotherapy. It is surprising, therefore, that the median interval to repeat surgery for LLC was as short as 6 months. Aizenberg et al. ${ }^{3 \mathrm{I}}$ in a series of ${ }^{\mathrm{I}} \mathrm{\text {spinal }}$ surgeries for unknown primaries, could find no relation between the completeness of resection and local recurrence rate. Other authors have reported low recurrence rates after total en bloc excisions. ${ }^{9,26,27}$ In our study, we were unable to confirm a relationship between more aggressive tumor removal and decreased local recurrence.

A methodologic limitation of the current study is that LLC is defined by those patients who require surgery for LLC, rather than radiologic LLC. In our prospective surgical database, follow-up information was based on clinical outcome measures and radiologic data were not routinely collected. Nevertheless, asymptomatic or small radiologic recurrences may not require treatment, and therefore the critical threshold for recurrence is when patients require further treatment. Second, missing data might potentially introduce bias, although this effect was minimized by excluding patients who did not have a date of death documented and whose follow-up was $<$ I year. There is inevitable bias in a surgical database, in that patients that are considered not fit for surgery were excluded. Hence, the data on LLC in this database cannot be generalized to nonsurgical series. Since our data were collected over many years, we do not have sufficient data to analyze the influence of newer techniques, such as stereotactic radiotherapy, proton beam therapy, or newer medical treatments that are more recently available. Future analyses of new data will be able correct for these confounding variables and assess their impact on tumor recurrence and overall survival.

\section{CONCLUSIONS}

In patients who have had surgery for symptomatic spinal metastases, we found that the likelihood of repeat surgery for local tumor recurrence was not predicted accurately by preoperative presenting features. However, the incidence of symptomatic local recurrence warranting surgery was low $(3.0 \%)$. Although it is difficult to predict, at first presentation, which patients may require a second operation for tumor recurrence, factors associated with local recurrence were longer overall survival and favorable tumor biology. These patients were more likely to require repeat surgery. In clinical practice, the decision to operate again for recurrent tumor is a personalized decision, based on oncologic, neurologic, mechanical, and patient factors at the time of re-presentation. However, surgery should not be withheld due to a fatalistic attitude: the median survival after second surgery was 6.I months, and therefore repeat surgery is justifiable for selected patients.

\section{REFERENCES}

I. Patchell RA, Tibbs PA, Regine WF, Payne R, Saris S, Kryscio RJ, et al. Direct decompressive surgical resection in the treatment of spinal cord compression caused by metastatic cancer: a randomized trial. Lancet. 2005;366:643-648.

2. Ibrahim A, Boriani S, Grejs A, Mazel C. Does spinal surgery improve the quality of life for those with extradural (spinal) osseous metastases? An international multicenter prospective observational study of 223 patients. J Neurosurg (Spine). 2008;8:27I-278

3. Falavigna A, Righesso Neto O, Ioppi AE, Grasselli J. Metastatic tumor of thoracic and lumbar spine: prospective study comparing the surgery and radiotherapy vs external immobilization with radiotherapy. Arq Neuropsiquiatr. 2007;65:889-895.

4. Chen B, Xiao S, Tong X, Xu S, Lin X. Comparison of the therapeutic efficacy of surgery with or without adjuvant radiotherapy versus radiotherapy alone for metastatic spinal cord compression: a meta-analysis. World Neurosurg. 2015;83:1066-1073.

5. Kim JM, Losina E, Bono CM, Schoenfeld AJ, Collins JE, Katz JN, et al. Clinical outcome of metastatic spinal cord compression treated with surgical excision \pm radiation versus radiation therapy alone: a systematic review of literature. Spine. 2012;37:78-84
6. Akram $\mathrm{H}$, Allibone J. Spinal surgery for palliation in malignant spinal cord compression. Clin Oncol (R Coll Radiol). 2010;22:792-800.

7. Choi D, Crockard A, Bunger C, Harms J, Kawahara N, Mazel C, et al. Review of metastatic spine tumour classification and indications for surgery: the consensus statement of the Global Spine Tumour Study Group. Eur Spine J. 2010;19: 215-222.

8. Bauer HC, Wedin R. Survival after surgery for spinal and extremity metastases. Prognostication in 24I patients. Acta Orthop Scand. I995;66:I43-I46.

9. Tomita K, Kawahara N, Kobayashi T, Yoshida A, Murakami H, Akamaru T. Surgical strategy for spinal metastases. Spine. 2001;26:298-306.

Io. Tokuhashi Y, Matsuzaki H, Oda H, Oshima M, Ryu J. A revised scoring system for preoperative evaluation of metastatic spine tumor prognosis. Spine. 2005;30:2186-2I9I.

II. Bartels RH, Feuth $\mathrm{T}$, van der Maazen $\mathrm{R}$, Verbeek AL, Kappelle AC, André Grotenhuis J, et al. Development of a model with which to predict the life expectancy of patients with spinal epidural metastasis. Cancer. 2007;IIO:2042-2049.

I2. Cappucio M, Gasbarrini A, Van Urk P, Bandiera S Boriani S. Spinal metastasis: a retrospective study validating the treatment algorithm. Eur Rev Med Pharmacol Sci. 2008;I2:I55-I6o.
I3. Wang $\mathrm{M}$, Bünger $\mathrm{CE}$, Li $\mathrm{H}$, Sun $\mathrm{M}$, Helmig $\mathrm{P}$, Borhani-Khomani G, et al. Improved patient selection by stratified surgical intervention: Aarhus Spinal Metastases Algorithm. Spine J. 2015;I5:I554-1562.

I4. Yokogawa N, Murakami H, Demura S, Kato S, Yoshioka K, Hayashi H, et al. Perioperative complications of total en bloc spondylectomy: adverse effects of preoperative irradiation. PLOS One. 20I4; 9:eg8797.

I5. Lau D, Than KD, La Marca F, Park P. Independen predictors for local recurrence following surgery for spinal metastasis. Acta Neurochir. 2014;156:277-282.

I6. Jansson KA, Bauer HCF. Survival, complications and outcome in 282 patients operated for neurological deficit due to thoracic or lumbar spinal metastases. Eur Spine J. 2006;15:196-202.

I7. Weigel B, Maghsudi M, Neumann C, Kretschmer R, Müller FJ, Nerlich M. Surgical management of symptomatic spinal metastases. Postoperative outcome and quality of life. Spine. I999;24: 2240-2246.

I8. Quraishi NA, Rajabian A, Spencer A, Arealis G, Mehdian H, Boszczyk BM, et al. Reoperation rates in the surgical treatment of spinal metastases. Spine J. 2015;15(3 suppl):S37-43.

I9. Chataigner H, Onimus M. Surgery in spinal metastases without spinal cord compression: 
indications and strategy related to the risk of recurrence. Eur Spine J. 2000;9:523-527.

20. Laufer I, Hanover A, Lis E, Yamada Y, Bilsky M. Repeat decompression surgery for recurrent spinal metastases. J Neurosurg (Spine). 2010;I3:I09-II5.

2I. Choi D, Fox Z, Albert T, Arts M, Balabaud L, Bunger C, et al. Prediction of quality of life and survival after surgery for symptomatic spinal metastases: a multicenter cohort study to determine suitability for surgical treatment. Neurosurgery. 2015;77:698-708.

22. Choi D, Crockard HA. How and why should we benchmark clinical outcomes and quality of life for surgery in spinal metastases? Br J Neurosurg. 2009;23:3-4.

23. Amelot A, Balabaud L, Choi D, Fox Z, Crockard HA, Albert T, et al. Surgery for metastatic spine tumors in the elderly. Advanced age is not a contraindication to surgery!. Spine J. 2017;17:759-767.

24. Tomita K, Kawahara N, Baba H, Tsuchiya H, Fujita T, Toribatake Y. Total en bloc spondylectomy. A new surgical technique for primary malignant vertebral tumors. Spine. 1997;22:324-333.

25. Lau D, Leach MR, La Marca F, Park P. Independent predictors of survival and the impact of repeat surgery in patients undergoing surgical treatment of spinal metastasis. J Neurosurg Spine. 20I2;17:565-576.

26. Yoshioka K, Murakami H, Demura S, Kato S, Kawahara N, Tomita K, et al. Clinical outcome of spinal reconstruction after total en bloc spondylectomy at 3 or more levels. Spine. 20I3;38:EI5II-I5I6.
27. Kato S, Murakami H, Demura S, Yoshioka K, Kawahara N, Tomita K, et al. More than Io-year follow-up after total en bloc spondylectomy for spinal tumors. Ann Surg Oncol. 2014;21:1330-1336.

28. Luzzati AD, Shah S, Gagliano F, Perrucchini G, Scotto G, Alloisio M. Multilevel en bloc spondylectomy for tumors of the thoracic and lumbar spine is challenging but rewarding. Clin Orthop Relat Res. 2015;473:858-867.

29. Boriani S, Biagini R, De Iure F, Bertoni F, Malaguti MC, Di Fiore M, et al. En bloc resections of bone tumors of the thoracolumbar spine. A preliminary report on 29 patients. Spine. I996;2I: I927-I93I.

3o. Dosquet C, Coudert MC, Lepage E, Cabane J, Richard F. Are angiogenic factors, cytokines, and soluble adhesion molecules prognostic factors in patients with renal cell carcinoma? Clin Cancer Res. I997;3:245I-2458.

3I. Aizenberg MR, Fox BD, Suki D, McCutcheon IE Rao G, Rhines LD. Surgical management of un known primary tumors metastatic to the spine. J Neurosurg Spine. 2012;16:86-92.

Conflict of interest statement: This work was funded by the Global Spine Tumour Study Group, a registered charity of England and Wales, Charity Commission number 1134934 and DePuy Synthes (Johnson and Johnson). This study was performed in part at University College London Biomedical Research Centre, which receives funding from the National Institute for Health Research, United Kingdom. M. Arts: stock or other ownership: Nuvasive, Stryker, Galapagos, and Pharming; consulting or advisory role: Amedica, Zimmer Biomet, Silony, and EIT; research funding: Zimmer Biomet,
Amedica, Intrinsics, and EIT; patent, royalties, other intellectual property: EIT. J. Buchowski: patent, royalties, other intellectual property interest: Globus Medical, K2M, and Wolters Kluwer Health; institutional fellowship support: AO Spine North America and OMeGA. M. Fehlings: consulting or advisory role: Pfizer, Zimmer Biomet, and InVivo Therapeutics. E. Massicotte: honoraria: AO Spine North America; travel, accommodations, expenses: AO Spine North America. C. Mazel: stock or other ownership: Amplitude, Honoraria: DePuy Spine, Medtronic, Zimmer; consulting or advisory role: Ethicon; Speakers' Bureau: DePuy Spine Medtronic; patents, royalties or other intellectual property: CHD; travel, accommodations, expenses: DePuy, Medtronic, Zimmer, Clariance. N. Quraishi: honoraria: AO Spine, Medtronic, DePuy Synthes; speakers' bureau: AO Spine, Medtronic, DePuy Synthes; travel, accommodations, expenses: AO Spine, Medtronic, DePuy Synthes; J. J. Verlaan: consulting or advisory role: DePuy Synthes (inst); educational grant: DePuy Synthes (inst). M. Wang: stock or other ownership: Innovative Surgical Devices, Spinicity consulting or advisory role: DePuy Spine, AesculapSpine, Jointax, K2M; research funding: Department of Defence, patents, royalties, other intellectual properties: Children's Hospital of LA, DePuy Spine, Springer Publishing, Quality Medical Publishing. D. Choi: research funding: DePuy Synthes (Inst)

Received 3 April 2018; accepted 23 April 2018

Citation: World Neurosurg. (2018).

https://doi.org/10.1016/j.wneu.2018.04.170

Journal homepage: www.WORLDNEUROSURGERY.org Available online: www.sciencedirect.com 1878-8750/\$ - see front matter (C) 2018 Elsevier Inc. All rights reserved. 